\title{
Granulocyte Neutral Proteases and Pseudomonas Elastase as Possible Causes of Airway Damage in Patients with Cystic Fibrosis
}

\author{
Susanne Suter, Urs B. Schaad, Laurent Roux, \\ Urs E. Nydegger, and Francis A. Waldvogel
}

\author{
From the Infectious Disease Division, Department of \\ Medicine, University Hospital, 12II Geneva 4; and the \\ Departments of Pediatrics, Universities of Geneva and \\ Bern, Switzerland
}

\begin{abstract}
We studied the possible role of granulocyte neutral proteases as mediators of airway destruction in patients with cystic fibrosis (CF) who were infected with Pseudomonas aeruginosa. We measured the enzymatic activities of bronchial secretions on purified radioactively labeled complement component three (C3), elastin, and a granulocyte elastase-specific substrate. Bronchial secretions from 18 patients with CF who were infected with $P$ aeruginosa had a significantly higher mean value for $\mathrm{C} 3$ cleaving, elastolytic, and granulocyte elastase-like activity than did two control groups. High enzymatic activities were observed in patients with CF who have advanced bronchial disease (that had been determined by a clinical scoring system). Kinetics of proteolysis of radioactively labeled C3 and inhibition profiles of the activities of the three enzymatic activities studied suggest that they are mainly derived from granulocytes. In addition, 20 of 31 strains of $P$ aeruginosa isolated from patients with CF inactivated purified $\alpha \mathbf{l}$-antiprotease in vitro. We postulate that granulocyte neutral proteases and $P$ aeruginosa may act synergistically in the airways of patients with $C F$ and may contribute to the destruction of elastin and inactivation of $\mathrm{C} 3$.
\end{abstract}

Cystic fibrosis is a fatal hereditary disease, in which the leading cause of death is respiratory failure [1]. Patients with cystic fibrosis (CF) usually have a long history of purulent bronchitis leading to progressive destruction of small bronchioles and followed by involvement of the large airways [2]. The pathogens most frequently associated with these respiratory-tract infections are Staphylococcus aureus and Pseudomonas aeruginosa [2, 3]. Clinical and pathological observations suggest that progressive airway destruction is accelerated during infections with $P$ aeruginosa [2]. However, little information is available regarding the mechanisms involved in progressive bronchiolar and bronchial damage and the persistence of $P$ aeruginosa in bronchial secretions.

Bronchial secretions from patients with $\mathrm{CF}$ con-

Received for publication July 21, 1983, and in revised form November 18, 1983.

Part of this work was supported by grant no. 3.836.0.79 from the Swiss Research Foundation.

We thank Anneliese Kahr and Sassi Dharan for technical assistance, W. Ruch for advice and suggestions, Dr. P. Naftolin and Dr. J.-D. Vassalli for reviewing the manuscript, and Françoise Michaud for secretarial assistance.

Please address requests for reprints to Dr. Susanne Suter, Infectious Disease Division, University Hospital, 1211 Geneva 4, Switzerland. tain numerous PMNs [2] that might contribute to airway damage by release of neutral proteases such as elastase, collagenase, cathepsin $\mathrm{G}$, and others [4, 5]. These enzymes are indeed able to destroy important structural proteins of the lung and its airways such as elastin, collagen, and proteoglycans $[4,5]$ in vitro; in addition, they can inactivate important opsonins such as complement component C3 [6-8] and IgG and IgM immunoglobulins [911]. It is also well established that they are released extracellularly during phagocytosis [12]. Furthermore, $P$ aeruginosa may secrete an elastase that destroys the two main inhibitors protecting the lung and its airways from the activity of PMN neutral proteases: al-antiprotease [13-16] and the bronchial mucosal proteinase inhibitor [17]. In addition, this bacterial elastase is also active on $\mathrm{C} 3$ [18] and elastin [15].

We therefore measured the enzymatic activities of bronchial secretions from patients with $C F$ (who were infected with $P$ aeruginosa) on purified human $\mathrm{C} 3$, bovine elastin, and a granulocyte elastase-specific substrate. Two groups of patients with bronchial secretions rich in PMNs (one group with and the other without bacterial infection of the tracheobronchial tree) and a granular enzyme preparation isolated from human PMNs were used as controls. 
Table 1. Description of patients with cystic fibrosis.

\begin{tabular}{|c|c|c|c|c|}
\hline \multirow[b]{2}{*}{$\begin{array}{l}\text { Patient } \\
\text { no. }\end{array}$} & \multirow[b]{2}{*}{$\begin{array}{c}\text { Age } \\
\text { (years) }\end{array}$} & \multicolumn{3}{|c|}{ Clinical scores } \\
\hline & & $\begin{array}{c}\text { Status } \\
\text { and activity }\end{array}$ & $\begin{array}{l}\text { Pulmonary } \\
\text { findings }\end{array}$ & $\begin{array}{c}\text { Bacteriology } \\
\text { of sputum }\end{array}$ \\
\hline 1 & 18 & 4 & $4-5$ & 4 \\
\hline 2 & 18 & $4-5$ & 4 & 4 \\
\hline 3 & 14 & 2 & 3 & 4 \\
\hline 4 & 20 & $3-4$ & 4 & 4 \\
\hline 5 & 11 & 2 & 3 & 4 \\
\hline 6 & 9 & $2-3$ & 4 & 4 \\
\hline 7 & 14 & $2-3$ & 3 & $3-4$ \\
\hline 8 & 18 & 2 & $2-3$ & 3 \\
\hline 9 & 6 & $1-2$ & 3 & $3-4$ \\
\hline 10 & 20 & $3-4$ & 4 & 4 \\
\hline 11 & 14 & 4 & 4 & 4 \\
\hline 12 & 10 & 2 & 3 & $3-4$ \\
\hline 13 & 18 & $2-3$ & 3 & 4 \\
\hline 14 & 6 & 2 & 3 & 3 \\
\hline 15 & 5 & 2 & 2 & 3 \\
\hline 16 & 5 & 2 & 3 & 4 \\
\hline 17 & 16 & $4-5$ & 5 & 5 \\
\hline 18 & 6 & 4 & 4 & 4 \\
\hline
\end{tabular}

NOTE. The scores of the patients were determined according to the scoring system of Kraemer et al. [23] by one of the authors (U.B.S.) unaware of the results of the activities measured in bronchial secretions.

\section{Patients and Methods}

Group 1. Twenty-four samples of bronchial secretions were collected after chest physiotherapy from 18 patients with $\mathrm{CF}$, all of whom had $P$ aeruginosa infections (table 1). The patients were either attending cystic fibrosis clinics or were inpatients at the children's hospitals, University of Bern or Geneva, Switzerland. The diagnosis of cystic fibrosis had been established on clinical features of the disease and confirmed by sweat sodium and chloride concentrations above $70 \mathrm{meq} / \mathrm{l}$. The clinical and pulmonary conditions of the patients were determined by one of the authors who was unaware of the laboratory results and were recorded via a scoring system outlined previously [19].

All but two patients were on similar antibiotic treatment when the secretions were collected. The mean age of the patients was 13 years (range, 5-20 years).

Group 2. Twenty samples of bronchial secretions, which fulfilled the quality criteria established by Murray and Washington [20], were collected from 20 patients with acute exacerbations of chronic bronchitis, as documented by chronic cough, purulent sputum, positive chest findings, and roentgenograms. In nine patients bronchiectases had been documented by bronchography or bronchoscopy. Bronchial lavage fluid was obtained from six patients by bronchoscopy on the same day that the sputum samples were obtained. Pathogens isolated from sputum included: Haemophilus influenzae [18], Streptococcus pneumoniae [8], Escherichia coli [1], Proteus vulgaris [1], $S$ aureus [5], and Aspergillus [1]. Three patients had mixed infections. Eighteen patients had a history of smoking. The mean age of the patients was 50 years (range, 9-62 years).

Group 3. Ten samples of bronchial secretions were obtained as morning specimens from 10 patients who had no evidence of acute or chronic respiratory-tract infection. Diagnosis included: acute asthma (2), pulmonary embolism (1), emphysema with chronic respiratory failure (1), chronic heart failure (3), bronchial carcinoma (1), and metastatic cancer of the lung (1). All patients produced sputum that was negative when cultured for pathogens. The mean age of the patients was 68 years (range, 22-90 years).

Processing of bronchial secretions and of $P$ aeruginosa isolates. Bacterial cultures and identifications were performed according to wellestablished methods. Leukocyte counts in bronchial secretions were evaluated semiquantitatively [20], by a technician unaware of the study results. The secretions were mixed with a half volume of sterile isotonic saline and centrifuged within $1 \mathrm{hr}$ at $1,000 \mathrm{~g}$ until the supernatant was clear. The supernatants were frozen at $-70 \mathrm{C}$ until tested. Protein concentration was determined by a standard method (Bio-Rad, Richmond, Calif).

Thirty-one strains of $P$ aeruginosa were isolated from the bronchial secretions of patients with $\mathrm{CF}$ who were infected with $P$ aeruginosa; the cultures were maintained in skim milk at $-20 \mathrm{C}$.

Microbiological techniques. In order to test the $P$ aeruginosa strains for elastase production, quantitative cultures were performed as follows: $0.1 \mathrm{ml}$ of an overnight culture was added to $5 \mathrm{ml}$ of Mueller-Hinton broth and incubated in a shaking waterbath at $37 \mathrm{C}$ for $24 \mathrm{hr}$. The size of the inoculum and the final bacterial concentration were determined by making plates of serial dilutions on Mueller-Hinton agar and counting the colony forming units. The 24-hr cultures were centrifuged in an Eppendorf centrifuge at 8,000 $\mathrm{g}$ for $10 \mathrm{~min}$ (Eppendorf, Hamburg, FRG). The supernatants were frozen at $-70 \mathrm{C}$ in small aliquots until used.

Purification of human C3, labeling of C3 with ${ }^{125}$ I and preparation of ${ }^{125}$ I-labeled C3-Sepharose. C3 was purified to homogeneity from human 
plasma with the use of the method of Tack and Prahl [22]. It was labeled with ${ }^{125}$ I (Amersham International, Amersham, England), by means of the chloramine T method [23]. Approximately $1 \times$ $10^{6}$ counts per minute $(\mathrm{cpm})$ were incorporated into $1 \mu \mathrm{g}$ of purified C3. Labeled C3 was either used directly or it was coupled to $\mathrm{CnBr}$-activated Sepharose 4B (Pharmacia Fine Chemicals, Uppsala, Sweden) by a standard method.

Assessment of calcium- and magnesium-independent C3-cleaving activity. In order to rule out C3-cleaving activity deriving from complement convertases, these experiments were performed in the presence of EDTA $(20 \mathrm{mmol}$ final concentration). ${ }^{125}$ I-labeled C3-Sepharose beads corresponding to $2 \times 10^{5} \mathrm{cpm}$ were suspended in $150 \mu \mathrm{l}$ of calcium- and magnesium-free Dulbecco's PBS (pH 7.4) and incubated with $50 \mu \mathrm{l}$ of bronchial secretions that had been previously mixed with EDTA (20 mmol final concentration), with granular enzymes, or with $P$ aeruginosa culture supernatants at $37 \mathrm{C}$ for $5 \mathrm{hr}$. ${ }^{125}$ I-labeled $\mathrm{C} 3$ fragments were separated from ${ }^{125} \mathrm{I}$-labeled C3-Sepharose beads by centrifugation at $8,000 \mathrm{~g}$ for $5 \mathrm{~min}$. Cleavage of $\mathrm{C} 3$ was expressed as the percentage of $\mathrm{cpm}$ in the supernatant divided by the $\mathrm{cpm}$ of the total sample. Spontaneous breakdown of ${ }^{125} \mathrm{I}-$ labeled $\mathrm{C} 3$ incubated alone was $1.2 \% \pm 0.2 \%$; this background was subtracted from the results.

Demonstration of proteolysis of ${ }^{125}$ I-labeled C3 by polyacrylamide gel electrophoresis [24]. The kinetics of proteolysis and the pattern of breakdown products of ${ }^{125}$ I-labeled $\mathrm{C} 3$ generated by the bronchial secretions from a patient with $\mathrm{CF}$ and a $P$ aeruginosa infection were compared with those obtained from the culture supernatant of a strain of $P$ aeruginosa from the same patient, and with those observed when granular enzymes were used.

Four microliters of a bronchial secretion, $34 \mu \mathrm{l}$ of granular enzymes and $240 \mu$ l of the supernatant from a $P$ aeruginosa culture were incubated with labeled $\mathrm{C} 3$ corresponding to $5 \times 10^{6} \mathrm{cpm}$ in Tris$\mathrm{NaCl}$ buffer (pH 7.4) in a total volume of $600 \mu \mathrm{l}$. Aliquots of $25 \mu 1$ were withdrawn after $0,2,5,8$, $13,20,30,60,120$, and 300 minutes of incubation at $37 \mathrm{C}$ and mixed with $12.5 \mu \mathrm{l}$ of SDS sample buffer $(1 \%$ 2-mercaptoethanol, $2 \%$ SDS, $80 \mathrm{mmol}$ Tris-HCl pH 6.8, $10 \%$ glycerol, and $0.05 \%$ bromophenol-blue) and heated at $100 \mathrm{C}$ for $3 \mathrm{~min}$. The samples were run on discontinuous slab gels with $5 \%(\mathrm{wt} / \mathrm{vol})$ acrylamide in the stacking gel and $12.5 \%(\mathrm{wt} / \mathrm{vol})$ acrylamide in the resolving gel. Proteins were revealed by autoradiography with a
Kodak X-omat S film with exposure at $-70 \mathrm{C}$ for $3 \mathrm{hr}$. Monitoring of molecular weights was accomplished with the use of Sendai virus proteins [25], which were labeled with $\left.{ }^{35} \mathrm{~S}\right]$ methionine as marker proteins with known molecular weights. Controls included ${ }^{125}$ I-labeled $\mathrm{C} 3$ incubated both alone and with saliva from two patients with $\mathrm{CF}$ and $P$ aeruginosa infections and from one normal individual.

Preparation of granular enzymes from human $P M N s$. Granular enzymes were prepared from PMNs collected from fresh heparinized blood of normal adult volunteers, according to the method of Baggiolini [21] and modified as previously described [8]. They had an elastolytic activity of 17.4 $\mathrm{U}_{\mathrm{E}}$ and granulocyte elastase-like activity of $0.59 \mathrm{U}_{\mathrm{TGP}}$ (see below for definition of units).

Assessment of elastolytic activity. Elastolytic activity was measured as described by Hornebeck [26] with purified bovine elastin (Sigma Co, St. Louis) radioactively labeled with ${ }^{3} \mathrm{H}$ (New England Nuclear Corp, Boston). Ten microliters of the test sample were incubated with $500 \mu \mathrm{g}$ of ${ }^{3} \mathrm{H}$-labeled elastin suspended in $1 \mathrm{ml}$ of Tris $(0.1$ $M, \mathrm{pH} 8.2)$ containing Brij $35(0.01 \%)$ and sodium azide $(0.02 \%)$, for $16 \mathrm{hr}$ at $37 \mathrm{C}$. The samples were then centrifuged at $3,300 \mathrm{~g}$ for $10 \mathrm{~min}$. The radioactivity of $100 \mu \mathrm{l}$ of the supernatants was measured and used to calculate the amount of solubilized elastin. One milligram of completely solubilized ${ }^{3} \mathrm{H}$-labeled elastin corresponded to $145,000 \mathrm{cpm}$. Elastolytic activity $\left(U_{E}\right)$ was expressed as the number of milligrams of labeled elastin solubilized by $1 \mathrm{ml}$ of enzyme solution.

Measurement of granulocyte elastase-like activity. Granulocyte elastase-like activity was measured as previously described [8] with the use of synthetic Suc-Ala-Ala-Pro-Val-7-amino-4-methyl coumarin (TGP 928; a gift from M. Baggiolini, Wander Research Institute, Bern, Switzerland) as a substrate. The sequence Ala-Ala-Pro-Val has been shown to be a specific substrate for granulocyte elastase [27].

The enzymatic activity was expressed in $U_{T G P}$ $=$ micromoles of 7-amino-5-methyl-coumarin solubilized per minute by $1 \mathrm{ml}$ of enzyme solution (extinction coefficient at $360 \mathrm{~nm}=12,300$ ). $P$ aeruginosa culture supernatants, Mueller-Hinton broth, saliva from two patients with $\mathrm{CF}$ and from one normal individual had no activity on this substrate.

Inactivation of partially purified $\alpha-1$ antiprotease by supernatants of $P$ aeruginosa cultures. $\alpha-1$ antiprotease inactivation was measured as follows: 
first, inhibition of $50 \mu \mathrm{l}$ of granular enzyme by increasing concentrations of partially purified $\alpha-1$ antiprotease (Sigma) was measured; a $100 \%$ inhibition was reached by a concentration of $10 \mu \mathrm{g}$ of $\alpha-1$ antiprotease (in $10 \mu \mathrm{l}$ ). Thereafter, samples of $30 \mu$ l of supernatants of $P$ aeruginosa cultures were incubated with $60 \mu \mathrm{l}$ of Dulbecco's PBS (pH 7.4) containing $60 \mu \mathrm{g}$ of $\alpha-1$ antiprotease at $37 \mathrm{C}$ for 24 $\mathrm{hr}$, and the inhibitory activity of $15 \mu \mathrm{l}$ of this incubation mixture was tested on $50 \mu \mathrm{l}$ of granular enzyme. $\alpha-1$ antiprotease incubated alone at $37 \mathrm{C}$ for $24 \mathrm{hr}$ kept its full inhibitory capacity on granular enzymes; Mueller-Hinton broth had no effect on either granular enzymes or TGP 928.

Inhibition experiments. Phenylmethylsulfonylfluoride (PMSF, Sigma) [28] was used at $2 \mathrm{mmol}$ final concentration, Ac-(Ala)4-chloromethylketone at $1 \mathrm{mmol}$ (kindly provided by Dr. J. Powers, Georgia Institute of Technology, Atlanta) [29], partially purified $\alpha-1$ antiprotease at $10 \mu \mathrm{mol}$, and Zincov [30] at $500 \mu \mathrm{mol}$. The results were expressed as percent inhibition of the enzymatic activity of a sample. With Ac-(Ala)4-chloromethylketone the samples were preincubated for $60 \mathrm{~min}$, but with the other inhibitors the incubation was only for $5 \mathrm{~min}$.

Statistics. The results were expressed as mean \pm SEM. For comparison of groups, the Mann-
Whitney $U$ test or Spearman's correlation coefficient were used. Enzymatic activities within each group were compared by linear regression analysis by the method of least squares.

\section{Results}

Leukocyte quantitation and protein concentrations of bronchial secretions. Stained smears showed comparable mean leukocyte scores: group $1,2.3 \pm 0.2$ (range, $1-3$ ); group 2, $2.7 \pm 0.2$ (range, $2-3$ ); group 3, $2.1 \pm 0.1$ (range, 2-3). The three groups of bronchial secretions had a significantly different mean protein concentration: group 1, 6.3 $\pm 0.9 \mathrm{~g} / 1$ and group $2,5.1 \pm 0.5 \mathrm{~g} / 1$ were significantly higher than group $3,2.7 \pm 0.6 \mathrm{~g} / \mathrm{I}(P<.01)$.

Proteolytic and esterolytic activities in bronchial secretions (figure 1): ${ }^{125}$ I-labeled C3-cleaving activity. In group 1 the mean C3-cleaving activity was $48.8 \% \pm 2.5 \%$, a value significantly higher than that of group 2 , which was $15.4 \% \pm 3.5 \%$ ( $P$ $<.001)$ and of group 3, which was $7.6 \% \pm 0.9 \%$ $(P<.001)$. The difference between groups 2 and 3 was also significant $(P<.001)$. The same held true when the results were expressed per gram of protein.

Elastolytic activity. The mean elastolytic activ-

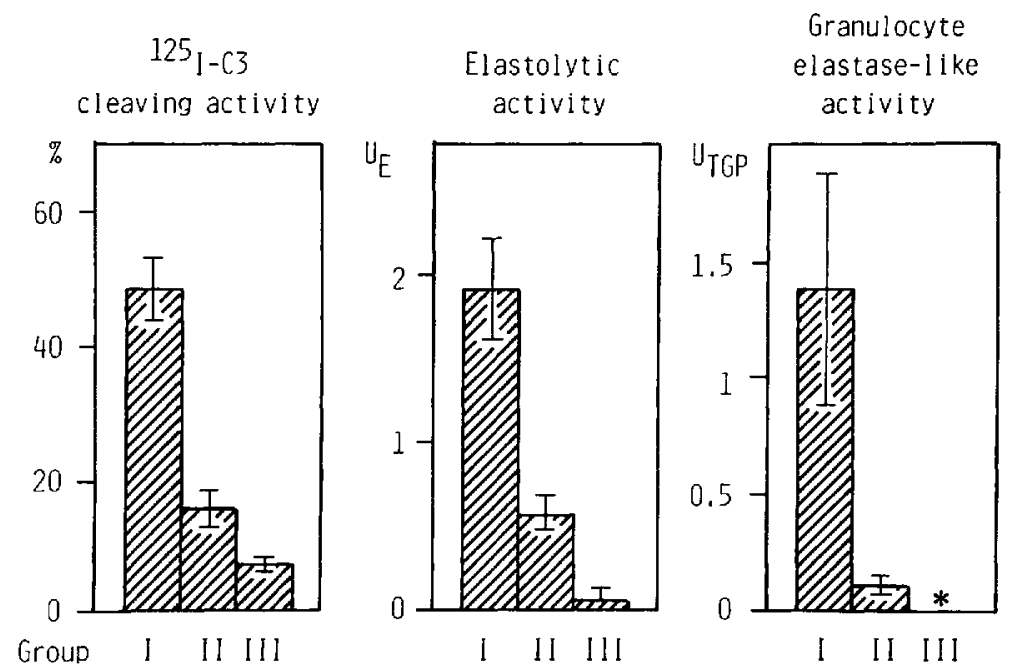

Figure 1. Three enzyme activities were measured in bronchial secretions from three groups of patients: Group 1, patients with CF infected with $P$ aeruginosa; group 2, patients with exacerbated chronic bronchitis; group 3, patients with various noninfectious conditions, but with significant numbers of granulocytes in their bronchial secretions. C3-cleaving activity was determined by measuring the radioactivity of 125 I-labeled C3 fragments released into the supernatant from ${ }^{125}$ I-labeled C3-Sepharose after incubation with $50 \mu \mathrm{l}$ of the bronchial secretion for $5 \mathrm{hr}$ at $37 \mathrm{C}$. The results were expressed as the percentage of radioactivity in the supernatant divided by the radioactivity of the total sample. Elastolytic activity $\left(\mathrm{U}_{\mathrm{E}}\right)$ was expressed as milligrams of ${ }^{3} \mathrm{H}$-labeled elastin hydrolyzed by $1 \mathrm{ml}$ of enzyme solution after $16 \mathrm{hr}$ of incubation at $37 \mathrm{C}$. Granulocyte elastase-like activity was measured as $\mathrm{U}_{\mathrm{TGP}}=$ micromoles of 7-amino-5-methyl-coumarin released $/ \mathrm{min}$ per milliliter of enzyme solution. 
ity of group 1 was $1.9 \pm 0.3 \mathrm{U}_{\mathrm{E}}$ compared with $0.54 \pm 0.09(P<.05)$ in group 2 and $0.04 \pm 0.02$ $(P<.001)$ in group 3. The difference between groups 2 and 3 was also significant $(P<.01)$. These differences were also significant when expressed per gram of protein.

Granulocyte elastase-like activity. The mean granulocyte elastase-like activity was strikingly higher in group 1 than in group 2 bronchial secretions: $1.39 \pm 0.56 \mathrm{U}_{\mathrm{TGP}}$ vs. $0.12 \pm 0.05 \mathrm{U}_{\mathrm{TGP}}(P$ $<.001$ ). Group 3 samples had no detectable granulocyte elastase-like activity, as was the case in saliva obtained from two patients with $C F$ and $P$ aeruginosa infections and one normal individual.

In group 1 patients, high clinical scores (which indicated poor pulmonary condition) correlated with high ${ }^{125}$ I-labeled C3-cleaving activity $\left(r_{\mathrm{s}}=\right.$ $.62, P<.01)$, elastolytic activity $\left(r_{\mathrm{s}}=.81, P\right.$ $<.001)$, and granulocyte elastase-like activity $\left(r_{\mathrm{s}}=.73, P<.01\right)$.

Since the activities of the three enzymes measured could possibly be attributed to the presence of PMN neutral proteases $[6-8,29]$, correlations between enzymatic activities within each group were calculated. Group 1: a linear correlation was found between ${ }^{125} \mathrm{I}$-labeled $\mathrm{C} 3$-cleaving and granulocyte elastase-like activity $(r=.49, P<.025)$
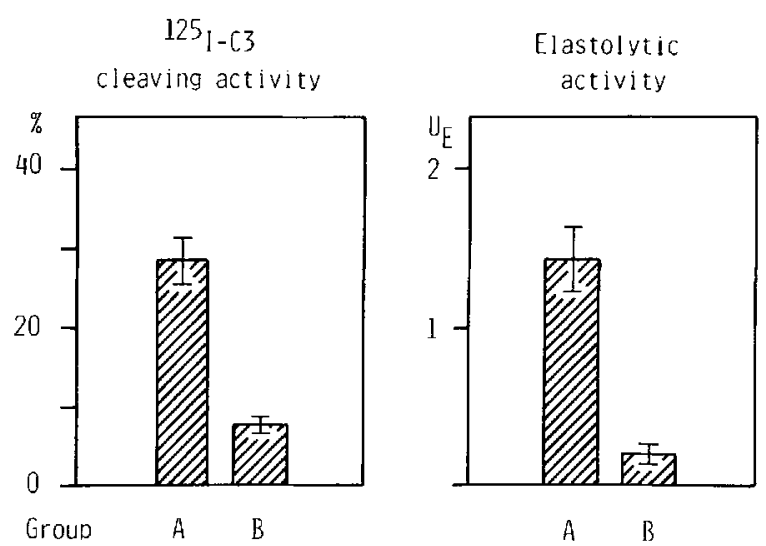

Figure 2. The results of enzymatic activities of the 24 hr culture supernatants of 31 strains of $P$ aeruginosa isolated from the patients with CF (group 1) on the substrates ${ }^{125}$ I-labeled $\mathrm{C} 3$-Sepharose and ${ }^{3} \mathrm{H}$-labeled elastin were determined in vitro as described for figure 1. Group A represents 20 strains of $P$ aeruginosa inactivating $\alpha-1$ antiprotease as described in material and methods and group B, 11 strains without effect on $\alpha-1$ antiprotease. Group A strains were considered as elastase-producing strains on the basis of their activity on the three substrates $\alpha-1$ antiprotease, ${ }^{125} \mathrm{I}$-labeled $\mathrm{C} 3$-Sepharose, and ${ }^{3} \mathrm{H}$ labeled elastin [18-21]. and between elastolytic and granulocyte elastaselike activity $(r=.89, P<.001)$. Group 2 ; a linear correlation was observed between ${ }^{125}$ I-labeled C3cleaving and granulocyte elastase-like activity $(r$ $=.48, P<.025$ ), between elastolytic and granulocyte elastase-like activity $(r=.56, P<.01)$, and between $C 3$-cleaving and elastolytic activity $(r=.49, P<.025)$.

Heating of both bronchial secretion samples from three patients with $\mathrm{CF}$ and granular enzymes showed that incubation at $56 \mathrm{C}$ for $30 \mathrm{~min}$ inactivated only $10 \%$ of the ${ }^{125}$ I-labeled C3-cleaving activity of these samples, a finding consistent with the heat resistance of PMN elastase found by others [31].

Proteolytic activities of $P$ aeruginosa isolates from patients with $C F$ (figure 2). The mean bacterial concentration of quantitative $P$ aeruginosa cultures was $3.9 \pm 0.4 \times 10^{8} \mathrm{cfu} / \mathrm{ml}$. The culture supernatants were tested for $P$ aeruginosa elastase by measuring their activity on three substrates known to be cleaved by $P$ aeruginosa elastase in vitro: $\alpha$-1 antiprotease [15, 16], ${ }^{125}$ I-labeled C3 [14], and ${ }^{3} \mathrm{H}$-labeled elastin [13]. Twenty of the 31 strains of $P$ aeruginosa were shown to inactivate $\alpha-1$ antiprotease in vitro, as measured by a functional assay: $30 \mu \mathrm{l}$ of the culture supernatants of 20 $P$ aeruginos $a$ strains inactivated $60 \mu \mathrm{g}$ of $\alpha-1$ antiprotease completely. The 20 strains inactivating $\alpha-1$ antiprotease in vitro (figure 2 , group $\mathrm{A}$ strains) also had a significantly higher ${ }^{125}$ I-labeled C3cleaving activity $(29.6 \% \pm 3.3 \%)$ and elastolytic activity $\left(1.45 \pm 0.31 \mathrm{U}_{\mathrm{E}}\right)$ than did the 11 remaining strains (figure 2, group B strains). C3-cleaving activity of these strains was $7.6 \% \pm 1 \%$ and elastolytic activity $0.24 \pm 0.05 \mathrm{U}_{\mathrm{E}}(P<.001)$. In group $\mathrm{A}$ strains there was a linear correlation between ${ }^{125}$ Ilabeled C3-cleaving and elastolytic activity ( $r$ $=.88, P<.001$ ). Finally, there was no correlation between mucoid appearance and enzyme secretion of a particular strain; nine group A strains and four group B strains were mucoid.

Comparison of proteolytic and esterolytic activities. With these results at hand, we tried to determine whether the levels of enzymatic activity measured in secretions from patients with $C F$ were mainly due to enzymes originating from PMNs or from Pseudomonas strains. To make these determinations, we used time-course and biochemical patterns of ${ }^{125}$ I-labeled $\mathrm{C} 3$ proteolysis as well as inhibition experiments for differentiation.

Time course and pattern of proteolysis of ${ }^{125} \mathrm{I}$ - 


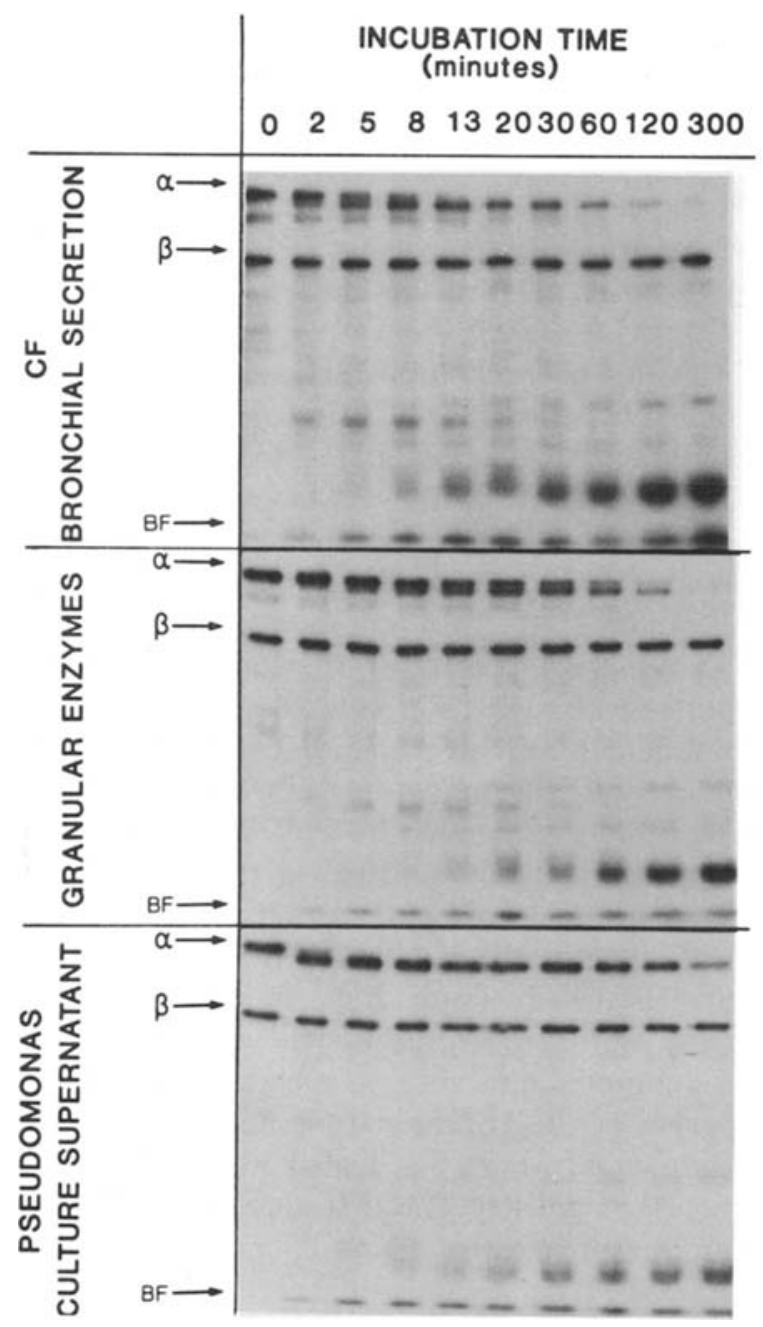

Figure 3. Four microliters of a cystic fibrosis bronchial secretion, $34 \mu \mathrm{l}$ of granular enzymes, and $240 \mu \mathrm{l}$ of the culture supernatant of the elastase-producing strain of $P$ aeruginosa from the same patient were incubated at $37 \mathrm{C}$ with ${ }^{125} \mathrm{I}$-labeled $\mathrm{C} 3$ at a concentration corresponding to $5 \times 10^{6} \mathrm{cpm}$ in a total volume of $600 \mu \mathrm{l}$ (Tris- $\mathrm{NaCl}$ buffer, $\mathrm{pH}$ 7.4). Aliquots of $25 \mu \mathrm{l}$ were withdrawn at various periods of incubation indicated in the figure. The timed samples were mixed with SDS sample buffer, heated at $100 \mathrm{C}$ for $3 \mathrm{~min}$, and the resulting breakdown of ${ }^{125}$ I-labeled $\mathrm{C} 3$ examined on a $12.5 \%$ polyacrylamide gel. The arrows $\alpha$ and $\beta$ designate the alpha- and betachain of ${ }^{125}$ I-labeled C3; BF corresponds to the buffer front. The observed proteolysis is restricted to the alphachain and the pattern of breakdown is similar for the bronchial secretion and for granular enzymes resulting in alpha-fragments with apparent molecular weights of $100 \times 10^{3}$ and $113 \times 10^{3}$ for the early incubation periods and small fragments of apparent molecular weights of 37. $\times 10^{3}, 25 \times 10^{3}$, and $18 \times 10^{3}$ at $5 \mathrm{hr}$ of incubation. Incubation with the $P$ aeruginosa culture supernatant lead to only one apparent cleavage of the alpha-chain with a fragment of apparently $110 \times 10^{3}$ and two small frag- labeled C3. Time course and pattern of proteolysis of ${ }^{125}$ I-labeled $\mathrm{C} 3$ induced by a bronchial secretion from a patient with $\mathrm{CF}$, by the $P$ aeruginosa culture supernatant of the elastase-producing strain from the same patient, and by the granular enzyme preparation were studied in detail as shown in figure 3. Identical patterns of breakdown of ${ }^{125}$ I-labeled $\mathrm{C} 3$ by the bronchial secretion and by the granular enzyme preparation can be recognized: both preparations caused a breakdown of the alpha chain of ${ }^{125}$ I-labeled C3 into fragments with apparent molecular weights of $113 \times 10^{3}$ and $100 \times 10^{3}$ and later, $32 \times 10^{3}, 25 \times 10^{3}$, and 18 $\times 10^{3}$. In contrast, incubation of ${ }^{125}$ I-labeled C3 with the culture supernatant of the elastase-producing strain of $P$ aeruginosa led to a single cleavage of the alpha chain with generation of an alpha fragment of an apparent molecular weight of 110 $\times 10^{3}$ and later, two small breakdown products of $16 \times 10^{3}$ and $17 \times 10^{3}$. Limited fragmentation of the alpha chain by too low an elastase concentration in the supernatant of the $P$ aeruginos $a$ culture was excluded by testing the culture supernatant undiluted, whereas the bronchial secretion and the granular enzyme preparation were assayed at dilutions of $1: 30$ and $1: 5$, respectively. ${ }^{125}$ I-labeled $\mathrm{C} 3$ incubated alone at $37 \mathrm{C}$ for $5 \mathrm{hr}$ showed no evidence of breakdown of either the alpha- or the beta-chain. Saliva from two patients with $\mathrm{CF}$ and $P$ aeruginosa infections and from one normal individual had no effect on ${ }^{125}$ I-labeled C3.

\section{Discussion}

In this study we found that bronchial secretions from patients with cystic fibrosis (CF) who had $P$ aeruginosa infections (group 1) had strikingly higher enzymatic activities on radioactively labeled $\mathrm{C} 3$ and elastin, as well as on a granulocyte elastasespecific peptide substrate, than did the bronchial secretions of two control groups, i.e., patients with chronic bronchitis (group 2) and patients without infection (group 3; figure 1). Most strains of $P$ aeruginosa isolated from the patients with $\mathrm{CF}$ secreted bacterial elastase in vitro (figure 2), as determined by the proteolytic activity of their culture supernatants on purified $\alpha-1$ antiprotease, C3,

ments of $16 \times 10^{3}$ and $17 \times 10^{3}$. Molecular weights were monitored with Sendai virus proteins as marker proteins [25]; the marker proteins are not shown on the figure. 
and elastin, all three of which are substrates for this enzyme [13-15, 18]. Each patient was infected with at least one elastase-producing strain of $P$ aeruginosa. The following arguments suggest that the proteolytic activities measured in bronchial secretions from patients with CF most likely derived from granulocyte neutral proteases, i.e., elastase and possibly cathepsin G. First, the timecourse of the appearance and the size of breakdown products of ${ }^{125}$ I-labeled C3 were identical when labeled C3 was incubated with bronchial secretions from patients with $C F$ and $P$ aeruginosa infection or with granular enzymes (figure 3 ), but it was clearly different when ${ }^{125} \mathrm{I}$-labeled C3 was incubated with a $P$ aeruginosa culture supernatant. Second, PMSF (an inhibitor of serine-proteases [28]) and Ac-(Ala)4-chloromethylketone (a granulocyte elastase-specific inhibitor [28]) substantially suppressed ${ }^{125}$ I-labeled C3-cleaving activity of both bronchial secretions from a patient with CF who had $P$ aeruginosa infections and granular enzymes, but not of supernatants from $P$ aeruginosa cultures (table 2). The contribution of complement convertases to ${ }^{125}$ I-labeled C3 breakdown was excluded by measuring ${ }^{125}$ I-labeled C3cleaving activity in the presence of EDTA. Among other proteases possibly involved in $\mathrm{C} 3$ cleavage by bronchial secretions from patients with CF who had $P$ aeruginosa infections, collagenase is in-

Table 2. Range of inhibition of ${ }^{125}$ I-labeled C3-cleaving and granulocyte elastase-like activity by PMSF and Ac(Ala)4-chloromethylketone.

\begin{tabular}{|c|c|c|}
\hline \multirow[b]{2}{*}{ Enzymatic activity } & \multicolumn{2}{|c|}{ Inhibition $(\%)$ by inhibitors* } \\
\hline & PMSF & $\begin{array}{l}\text { Ac-(Ala)4- } \\
\text { chloromethylketone }\end{array}$ \\
\hline $\begin{array}{l}\text { C3-cleaving activity of } \\
\text { CF bronchial secretions }\end{array}$ & & \\
\hline$(n=4)$ & $86-95$ & $73-89$ \\
\hline Granular enzymes & 95 & 83 \\
\hline $\begin{array}{l}P \text { aeruginosa culture } \\
\text { supernatants ( } 2 \text { strains) }\end{array}$ & 0 & 0 \\
\hline $\begin{array}{l}\text { Granulocyte elastase-like } \\
\text { activity of } \\
\text { CF bronchial secretions } \\
\text { Granular enzymes }\end{array}$ & $\begin{array}{l}100 \\
100\end{array}$ & $\begin{array}{l}95-100 \\
98\end{array}$ \\
\hline
\end{tabular}

NOTE. Granular enzymes and $P$ aeruginosa culture supernatants were tested in triplicate. Inhibition is expressed as $\%=$ $100-\left(\frac{\text { enzymatic activity with the inhibitor }}{\text { enzymatic activity without the inhibitor }} \times 100\right)$.

* The final concentration of the inhibitors was as follows: PMSF $=2.5 \mathrm{mmol}$, Ac-(Ala)4-chloromethylketone $=1 \mathrm{mmol}$. hibited by EDTA [28] and is also not inhibited by the two inhibitors used in the experiment.

Third, three elastases may contribute to measured elastolytic activity in bronchial secretions of patients with CF: (I) granulocyte elastase [32], a serine protease inhibited by PMSF [28], Ac-(Ala)4chloromethylketone [27], and its physiological inhibitor $\alpha-1$ antiprotease [16]; (2) pseudomonas elastase, a zinc-metalloprotease $[14,18]$ inhibited by Zincov [30]; and (3) macrophage elastase [32], which is a metalloprotease inhibited by $\alpha-2$ macroglobulin, but not by $\alpha-1$ antiprotease [31]. Our inhibition experiments show that the elastolytic activity of bronchial secretions from patients with $\mathrm{CF}$ was inhibited by the three inhibitors of granulocyte elastase, but not by the inhibitor of pseudomonas elastase (table 3). Macrophage elastase also has access to the lung [32], but this enzyme would not have been inhibited by the inhibitors used [31]. The only other enzyme also known to have some elastolytic properties [33] and similar inhibition patterns would be cathepsin G [28].

Fourth, although the substrate we used for measuring granulocyte elastase-like activity is specific for granulocyte elastase in purified systems [27], its specificity cannot be fully demonstrated in biological fluids. However, the complete inhibition of granulocyte elastase-like activity by PMSF and Ac-(Ala)4-chloromethylketone further characterized this activity as a serine protease such as elastase. In addition, the linear correlation found between C3-cleaving, elastolytic, and granulocyte elastase-like activity of bronchial secretions from patients with CF suggest that the three activities derive from the same group of enzymes. It should also be noted that when granulocyte elastase is complexed with $\alpha-2$ macroglobulin, its second less important inhibitor in vivo [34], the complex enzyme-inhibitor still has some activity on small peptide substrates similar to the one we used [35], but not on elastin. This may explain why granulocyte elastase-like activity of bronchial secretions from patients with CF compared with their elastolytic activity was so much higher than granulocyte elastase-like activity compared with elastolytic activity of granular enzymes.

Several aspects of our experimental design and clinical material must be considered. Collecting bronchial secretions from children is difficult; thus, we used adults as control patients. Bronchial secretions from cystic fibrosis patients with 
Table 3. Range of inhibition of elastolytic activity by various inhibitors.

\begin{tabular}{lcccc}
\hline & \multicolumn{4}{c}{ Inhibition (\%) by inhibitor* } \\
\cline { 2 - 5 } Enzyme source & PMSF & $\begin{array}{c}\text { Ac-(Ala)4- } \\
\text { chloromethylketone }\end{array}$ & $\alpha-1$ antiprotease & Zincov \\
\hline CF bronchial secretions $(n=10)$ & $88-97$ & $76-88^{\dagger}$ & $91-99$ & 0 \\
Granular enzymes & $87-93$ & 87 & $89-99$ & 0 \\
$P$ aeruginosa culture super- & & 6 & 0 & $87-88$ \\
$\quad$ natants (2 strains) & $4-6$ & & 0 \\
\hline
\end{tabular}

NOTE. Granular enzymes and $P$ aeruginosa culture supernatants were tested in triplicate. Inhibition is expressed as $\%=100-\left(\frac{\text { enzymatic activity with the inhibitor }}{\text { enzymatic activity without the inhibitor }} \times 100\right)$.

* The final concentration of the inhibitors was as follows: PMSF $=2 \mathrm{mmol}$, Ac-(Ala)4-chloromethylketone $=1 \mathrm{mmol}$, $\alpha-1$ antiprotease $=10 \mu \mathrm{mol}$, and Zincov $=500 \mu \mathrm{mol}$.

$\dagger n=3$.

$P$ aeruginosa infections were obtained by chest physiotherapy, since, in our centers, it is considered ethically unjustified to submit patients with $\mathrm{CF}$ to bronchial lavages, which have not demonstrated therapeutic value. Bronchial lavage fluids could be obtained from six of our control patients with chronic bronchitis on the same day as sputum samples. Proteolytic activities showed good correlation in the six sample pairs. Despite extensive research, we were unable to find more than three patients with CF who were not harboring small quantities of $P$ aeruginosa; these patients were the ideal control group. All three patients were under seven years of age, but had proteolytic activities comparable to adult patients with chronic bronchitis.

In our group of patients with $\mathrm{CF}$, high clinical scores, indicating poor pulmonary condition, correlated with high proteolytic activities in bronchial secretions. This finding may reflect a high degree of chronic infection leading to accumulation of larger numbers of PMNs or inactivation of the two most important inhibitors of granulocyte elastase in the lung by longstanding colonization or infection with $P$ aeruginosa. Indeed, $P$ aeruginosa elastase is known to inactivate both the bronchial mucosal proteinase inhibitor protecting the airways [36] and $\alpha-1$ antiprotease [16], and each patient with $C F$ was infected with at least one elastase-producing strain. Although we cannot link this in vitro demonstration with inactivation of inhibitors in vivo, the nearly complete suppression of elastolytic activity of $\mathrm{CF}$ bronchial secretions by purified $\alpha-1$ antiprotease in vitro indicates that in vivo the inhibitor potential for PMN neutral proteases was too.
Bronchial secretions from patients with $\mathrm{CF}$ also had high proteolytic activity on ${ }^{125}$ I-labeled $\mathrm{C3}$, an activity most likely originating from PMN neutral proteases. Since granulocyte elastase in vitro not only inactivates $C 3[6,7]$ but also $\operatorname{IgG}$ and $\operatorname{IgM}$ $[10,11]$, it is conceivable that free granulocyte elastase in vivo leads to functional inactivation of these opsonins and thereby favors the persistence of microorganisms, a well known characteristic of $P$ aeruginosa infections in these patients $[2,3]$.

From our observations we conclude that the high proteolytic activities measured in CF bronchial secretions most likely reflect the activity of PMN neutral proteases, especially elastase and cathepsin G. This free proteolytic activity may be caused by either an excess of proteolytic enzymes or a lowered local inhibitor potential, the latter being induced by $P$ aeruginosa elastase. PMN neutral proteases may also inactivate opsonins in the bronchial tree of these patients and therefore contribute to persistence of microorganisms. In a prospective study, we currently follow these proteolytic activities of bronchial secretions from patients with $C F$ who had $P$ aeruginosa infections before and after iv antibiotic therapy against $P$ aeruginosa and investigate the efficacy of synthetic inhibitors of granulocyte elastase on these proteolytic activities. Such inhibitors may be considered as possible adjuncts to antimicrobial therapy in patients with $\mathrm{CF}$.

\section{References}

1. Sant'Agnese PAD. Cystic fibrosis. In: Vaughan VC, McKay RJ, Behrman RE eds. Textbook of pediatrics. 11th ed. Philadelphia: WB Saunders Company, 1979:1988-2001 
2. Pennington JE, Wolff SM; Puziss M. Summary of a workshop on infections in patients with cystic fibrosis. $J$ Infect Dis 1979;140:252-6

3. Marks MI. The pathogenesis and treatment of pulmonary infections in patients with cystic fibrosis. J Pediatr 1981; 98:173-9

4. Janoff A, Sloan B, Weinbaum G, Damiano V, Sandhaus RA, Elias J, Kimbel R. Experimental emphysema induced with purified human neutrophil elastase: tissue localization of the instilled protease. Am Rev Respir Dis 1977;115:461-78

5. Sandberg LB, Soskel NT, Leslie JG. Elastin structure, biosynthesis and relation to disease states. $N$ Engl J Med 1981;304:566-79

6. Taylor JC, Crawford IP, Hugli TE. Limited degradation of the third component (C3) of human complement by human leukocyte elastase (HLE): partial characterization of C3 fragments. Biochemistry 1977:16:3390-6

7. Johnson U, Ohlsson K, Olsson I. Effects of granulocyte neutral proteases on complement components. Scand J Immunol 1976;5:421-6

8. Suter S, Nydegger UE, Roux L, Waldvogel FA. Cleavage of $\mathrm{C} 3$ by neutral proteases from granulocytes in pleural empyema. J Infect Dis 1981;144:499-508

9. Lew DP, Despont J-P, Perrin LH, Aguado M-T, Lambert PH, Waldvogel FA. Demonstration of a local exhaustion of complement components and of an enzymatic degradation of immunoglobulins in pleural empyema: a possible factor favouring the persistence of local bacterial infections. Clin Exp Immunol 1980;42:506-14

10. Prince HE, Folds JD, Spitznagel JK. Proteolysis of human IgG by human polymorphonuclear leucocyte elastase produces an $\mathrm{Fc}$ fragment with in vitro biological activity. Clin Exp Immunol 1979;37:162-8

11. Prince HE, Folds JD, Spitznagel JK. Interaction of human polymorphonuclear leukocyte elastase with human IgM. In vitro production of an Fab $\mu$-like fragment. Mol Immunol 1979;16:301-6

12. Stossel TP. Phagocytosis (second of three parts). N Engl J Med 1974;290:774-80

13. Moskowitz RW, Heinrich G. Bacterial inactivation of human serum alpha-1 antitrypsin. J Lab Clin Med 1971; 77:777-85

14. Morihara K, Tsuzuki H, Oda K. Protease and elastase of Pseudomonas aeruginosa: inactivation of human plasma $\alpha_{1}$-proteinase inhibitor. Infect Immun 1979;24: 188-93

15. Morihara K. Production of elastase and proteinase by Pseudomonas aeruginosa. J Bacteriol 1964;88:745-57

16. Gadek JE, Fells GA, Zimmermann RL, Rennard SI, Crystal RG. Anti-elastase of the human alveolar structures. Implications for the protease-antiprotease theory of emphysema. J Clin Invest 1981;68:889-98

17. Johnson DA, Carter-Hamm B, Dralle WM. Inactivation of human bronchial mucosal proteinase inhibitor by Pseudomonas aeruginosa elastase. Am Rev Respir Dis 1982; 126:1070-3

18. Schultz DR, Miller KD. Elastase of Pseudomonas aeruginosa: inactivation of complement components and complement-derived chemotactic and phagocytic factors. Infect Immun 1974;10:128-35
19. Kraemer R, Rüdeberg A, Kläy M, Rossi E. Relationship between clinical conditions, radiographic findings and pulmonary functions in patients with cystic fibrosis. Helv Paediatr Acta 1979;34:417-28

20. Murray PR, Washington JA II. Microscopic and bacteriologic analysis of expectorated sputum. Mayo Clinic Proc 1975;50:339-44

21. Baggiolini $M$. The isolation of granules from neutrophile polymorphonuclear leukocytes (PMNs). Methods Enzymol 1974;31:345-53

22. Tack BF, Prahl JW. Third component of human complement: purification from plasma and physiochernical characterization. Biochemistry 1976;15:4513-21

23. McConahey PJ, Dixon FJ. A method of trace iodination of proteins for immunologic studies. Int $\mathrm{Arch}$ Allergy Appl Immunol 1966;29:185-9

24. Laemmli UK. Cleavage of structural proteins during the assembly of the head of bacteriophage T4. Nature 1970; 227:680-5

25. Wagner RR, Prevec L, Brown F, Summers DF, Sokol F, MacLeod R. Classification of rhabdovirus proteins: a proposal. J Virol 1972;10:1228-30

26. Hornebeck W, Schnebli HP. Effect of different elastase inhibitors on leukocyte elastase pre-adsorbed to elastin. Hoppe-Seylers Z Physiol Chem 1982;363:455-8

27. Nakajima K, Powers JC, Ashe BM, Zimmermann M. Mapping the extended substrate binding site of cathepsin $\mathrm{G}$ and human leukocyte elastase. Studies with peptide substrates related to the $\alpha_{1}$-protease inhibitor reactive site. J Biol Chem 1979;254:4027-31

28. Schmidt W. Neutrale Proteasen aus menschlichen Leukozyten: Isolierung, Charakterisierung und biologische Wirkungen. Inaugural-Dissertation Fachbereich Chemie der Philipps-Universität Marburg/Lahn, Federal Republic of Germany, 1975:1-66

29. Powers JC, Gupton BF, Harley AD, Nishino N, Whitley RJ. Specificity of porcine pancreatic elastase, human leukocyte elastase and cathepsin G: inhibition with peptide chloromethyl ketones. Biochim Biophys Acta 1977; 485:156-66

30. Hudgin RL, Charleson SE, Zimmermann M, Mumford R, Wood PL. Enkephalinases: selective peptide inhibitors. Life Sci 1981;29:2593-2601

31. Hornebeck W, Bellon G, Brechemier D, Godeau G, Robert L. Control of elastic tissue destruction by elastase inhibitors. Progr Clin Biol Res 1981;54:233-46

32. Cohen AB. Potential adverse effects of lung macrophages and neutrophils. Fed Proc 1979;38:2644-7

33. Reilly $\mathrm{CF}$, Travis $\mathbf{J}$. The degradation of human lung elastin by neutrophil proteinases. Biochim Biophys Acta 1980; 621:147-57

34. Ohlsson K. $\alpha_{1}$-antitrypsin and $\alpha_{2}$-macroglobulin. Interactions with human neutrophil collagenase and elastase. Ann NY Açad Sci 1975;256:409-19

35. Harpel PC. Human alpha 2-macroglobulin. Methods Enzymol 1976;45:639-52

36. Hochstrasser K, Albrecht GJ, Schönberger OL, Rasche B, Lempart K. An elastase-specific inhibitor from human bronchial mucus: isolation and characterization. HoppeSeylers Z Physiol Chem 1981;362:1369-75 